\title{
Problem Concepts in Evolution Part II: Cause and Chance
}

\author{
Louise S. Mead • Eugenie C. Scott
}

Published online: 30 April 2010

(C) Springer Science+Business Media, LLC 2010

\begin{abstract}
In a previous article, we suggested that differences in how the general public and scientists use terms such as purpose and design can lead to confusion, particularly around understanding evolution and mechanisms of evolutionary change. Here, we present two additional problem concepts, cause and chance, and discuss how these concepts lead to confusion, suggesting how to address these specific challenges to understanding evolution in light of recent research in cognitive psychology and biological concept inventories.
\end{abstract}

Keywords Cause $\cdot$ Chance $\cdot$ Random $\cdot$ Methodological naturalism $\cdot$ Philosophical naturalism

Sinatra et al. (2008) suggest that "helping people to understand evolution is not a matter of adding on to their existing knowledge, but helping them to revise their previous models of the world to create an entirely new way of seeing," by specifically challenging default ways of thinking. The American student population is largely religious and a significant minority rejects evolution (Higher Education Research Institute 2005). In our experience, many students become mired in a false dichotomy: that acceptance of evolution requires rejection of a belief in God. We suggested in an earlier article (Mead and Scott 2010) that the differing scientific and student interpretations of two concepts commonly used in teaching evolution, purpose and design, may exacerbate such a position. Students regularly conflate their own existential meanings of these terms with scientific definitions.

L. S. Mead $(\bowtie) \cdot$ E. C. Scott

National Center for Science Education,

P.O. Box 9477, Berkeley, CA 94709-0477, USA

e-mail:mead@ncse.com
Just as the terms purpose and design may evoke supernatural explanations for many students, cause and chance can create similar problems - cause because it too can be interpreted to include supernatural explanations; chance because it can be interpreted to mean "purposeless" or "random" in the sense of meaninglessness. It is important for students to understand and use the scientific definitions in context because cause and chance/random are fundamental to explanations of mechanisms of evolutionary change. For example, a Concept Inventory of Natural Selection (Anderson et al. 2002) asks students to determine "[w]hat caused populations of birds having different beak shapes and sizes to become distinct species distributed on the various islands" and to know that "different beak types first arise in the Galapagos finches" because "changes in the finches' beaks occurred by chance"-in the sense of the change occurring independent of intention or need (emphasis added). Students need to have a clear understanding of how these concepts are used in the context of evolution.

\section{Cause: Proximate and Ultimate}

"Why" explanations seek to specify the cause of a phenomenon. For example, modern biologists might be interested in why some male gorillas disperse from the groups where they were born or why crossbills exhibit extensive adaptive radiation or why breeding pairs of ringbilled gulls adopt unrelated chicks. In most cases, modern biologists recognize two classes of causes: proximate and ultimate. Proximate causes in biology are invoked by explanations that answer questions about an organism over its lifetime (Ariew 2003) - for example, male gorilla dispersal may be caused by demographic and behavioral influences (Stoinski et al. 2009) — and often have to do with 
developmental or mechanistic causes. Ultimate causes in biology are associated with evolutionary explanations, the "making and changing of genetic programs" (Mayr 1993) for example, the data suggest that divergent selection for utilizing alternative resources is the ultimate cause of adaptive radiations in crossbills (Benkman 2003).

Rarely do biologists assume only proximate or only ultimate causes explain phenomena; rarely do they assume only one proximate or ultimate cause - instead, research in evolutionary biology typically seeks to disentangle the relative effects of these various causes. For example, why is it often the case that male birds are gaudy and female birds are drab? Answering the question in terms of proximate causes, a biologist would discuss the hormonal differences between males and females related to differences in the expression of alleles, limited to only one sex or repressed or promoted in only one sex by regulatory elements (Coyne et al. 2007). Answering the question in terms of ultimate causes, a biologist would reflect on the evolutionary history of the difference in plumage (Mayr 1993): given the existence of these genetically based differences that produce color variations in males and females, natural and sexual selection, drift, and migration, operating over many generations, cause the population to change with respect to these characters.

Like scientists, members of the nonscientific public recognize more than one level of causation. Although most people wouldn't use the terms proximate or ultimate in discussing, say, an arrhythmia, an abnormality in heart rhythm, they certainly wouldn't have any trouble distinguishing between the claim that a sudden cardiac arrest was due (proximately) to a specific malfunction in the heart's electrical system and the claim that the cardiac arrest was due (more ultimately) to a nutrient imbalance, an electrical shock, the consumption of illegal drugs, or a preexisting heart condition such as coronary artery disease. Nor would they have any trouble understanding that more proximate causes are compatible with more ultimate causes: that it could be reasonable to say that the cardiac arrest was caused by a specific malfunction and that it was also caused by a preexisting heart condition.

But there is a difference in their understanding of ultimate causes. Because ultimate causes have to be inferred, claims about them are more uncertain, and because such claims deal with more general phenomena at a more abstract and theoretical level, they can be harder to understand and assess. Since the public thinks that there are (or may be) ultimate causes of various phenomena, but is usually uncertain about or ignorant of what scientists think are (or might be) those causes, or consider natural causes alone to be insufficient, it is often tempting for the public to invoke divine causation in cases where natural ultimate causes are hard to discern and where doing so might reinforce existing religious or moral views.
For example, the proximate causes of the 2010 Haitian and Chilean earthquakes were movement of the tectonic plates upon which each nation sits. Most Americans understand that continents have moved over time (National Science Board 2010) and would understand that the proximate cause for the devastation was natural. Similarly, natural causes can readily be found to explain the difference between the greater degree of devastation suffered in Haiti than in Chile: the proximity of the Haitian quake epicenter to heavily populated Port-au-Prince as compared to the more rural epicenter in Chile, poorer building construction codes in Haiti than in Chile, and so forth. Evangelist Pat Robertson, however, while not denying the natural causes of the earthquake, explained that the ultimate cause of the devastation in Haiti was that its people "swore a pact to the devil" in the eighteenth century (Anonymous 2010) equating the ultimate cause for the earthquake with some type of supernatural, here diabolical, causation.

Because scientists cannot test supernatural hypotheses, they do not employ divine or diabolical activity in their explanations of natural phenomena. Students may need to have this point explicitly made-ultimate causation in biology does not employ supernatural explanations but rather natural, and in particular evolutionary, explanations. Given the perspectives of most of their students, teachers and professors should consider explaining the various types of causation. A key point to stress is that scientific hypotheses are testable. Proximate causes in biology are often observable, so students will have no problems understanding that hypotheses about proximate causes are testable. Ultimate causes in biology, as elsewhere, are typically inferred; yet, hypotheses about them are testable, too. Hypotheses about supernatural causes, however, are not testable. (Such hypotheses may include empirical elements that are testable, of course: the hypothesis that God created the universe about 6,000 years ago, for example, is testable, has been tested, and turns out to be false. But the hypothesis failed only with respect to the age of the universe; the broader hypothesis that God created the universe is unaffected by the failure of the narrower hypothesis.) So despite the temptations to think otherwise, ultimate explanations in science cannot invoke supernatural causation.

The purpose of this approach is to present science and evolution honestly, but in a way that does not slam shut the door of scientific understanding for students who are believers. When the different types of causation and their role in scientific thought are clearly stated, evolutionary explanations, which are testable explanations of natural phenomena in terms of natural causes, can take their place as valid scientific explanations - without forcing religious students (the majority in most classrooms) to choose between science and religion. Students may choose to 
accept, reject, or remain agnostic about supernatural explanations as long as they (and their teachers and professors) understand that in the science classroom the focus is on testable explanations.

\section{Chance and Randomness}

Within biology, a clear understanding of probability concepts such as chance and randomness is necessary for understanding evolutionary processes. However, the specialized meanings of these terms in science conflicts with the way they are understood outside of the discipline. In science, to talk about the chance of something happening is to claim that it will occur according to a known probability. To know the probability of a phenomenon allows a prediction of its occurrence. For example, a biologist might say that the chance (probability) of getting a homozygous recessive genotype in a heterozygous cross is one in four or that the types of observed mutations are the same frequency as expected by chance (Lynch et al. 2008). Confusingly for students, scientists also apply chance to unpredictable events to say that the outcome of a particular event is not predictable. For example, you might say that it is a matter of chance whether a child will be male or female, even though you can also say that the chance that it will be a male is equal to the chance that it will be a female. The origin of new genetic variations by mutation is another case in point: it is possible to predict probabilistically that new variation will arise, but it is not possible to predict whether a mutation will occur at a particular nucleotide site. Genetic drift is also often referred to as "changes occurring by chance," meaning that the gene or genotype frequency changes that occur are not due to natural selection, but to the vagaries of random sampling. So it is not surprising that students can be confused by "chance" since the term is used to describe phenomena as known as well as unknown.

In addition to the confusion that may arise within the classroom, additional sources of misunderstanding about the term chance come from "the street." Antievolutionists regularly contrast evolution as the result of chance (meaning directionless) processes with design (the result of the plan or purpose of the Creator). Intelligent design proponent Phillip Johnson wrote, "The important claim of evolution is that life developed gradually from nonliving matter to its present state of diverse complexity through purposeless natural mechanisms that are known to science" (Johnson 1991:33, emphasis added). Harking back to Paley's argument from design, creationists contend that complex structures such as the bacterial flagellum could not have occurred by chance (purposeless or directionless) processes in the same way that a Boeing 747 could not have assembled itself from airplane parts by a tornado blowing through a junkyard. Although creationists discuss the "improbability" of an amino acid sequence assembling by "chance," they use "by chance" primarily to mean "with no planning or purpose." The nonscientific public, encouraged by antievolutionists, contrasts "natural" with "designed," not realizing that a natural process such as natural selection can produce design, in the sense of complex, functioning structures.

Randomness, because it also deals with probability and predictability, is another problematic concept for biology students, many of whom, using a "street" rather than a mathematical definition, assume that random means "purposeless." Descriptions in the media of random violence, for example, are not claiming that everyone has an equal probability of being a victim, but that such violence is meaningless and purposeless. Garvin-Doxas and Klymkowsky (2008) reported that substantial difficulty in understanding molecular and evolutionary biology is associated with deep-seated misconceptions about random processes, noting that students believe that random processes are inefficient, whereas they regard biological systems as very efficient. Therefore, students mistakenly reason that randomness is irrelevant to biology-even though such processes in fact are important in many areas of the field. A lack of understanding of the role of random or stochastic processes in biology becomes even more important when applied to the topic of evolution: students believe that evolution requires a driving force, for example, that natural selection could not occur through random processes because they equate random with purposeless.

Scientists and mathematicians use random to suggest not purposelessness, but unpredictability, such as the random walk associated with Brownian motion or the random sampling of gametes that occurs in every population from one generation to the next, which in small populations, can result in substantial genetic drift-changes in allele frequencies that are not predictable given what is known about selection and allele frequencies. Nature is full of phenomena that are unpredictable (or unpredictable given our current knowledge); for example, biologists refer to events such as the Cretaceous-Tertiary asteroid impact as a "random" cause in this sense. When teachers and professors use terms like random and chance in so many differing ways, it is not surprising that students get them confused. We urge teachers to be explicit about how the terms are used in a given context to avoid these misunderstandings.

Further complicating the picture, most students do not understand the role that chance plays in evolution and natural selection. Evolution refers to the inference of common ancestry of living things and involves differential reproduction; some individuals (or genotypes) leave more or fewer offspring than others. Some differential reproduction is due to chance (random sampling), and 
some, to the positive or negative value of genetically determined traits in a particular environment (natural selection). So while chance factors are involved in evolution, natural selection is the antithesis of the public view of chance. Natural selection is adaptive differential reproduction, and adaptive is the key to understanding this principle. That natural selection is adaptive means by definition it is not a chance process. Chance (probability) is relevant to natural selection only in relation to the production of the genetic variation on which natural selection depends. Even so, it must be made clear to students that this use of chance is the scientists' probabilistic term, not the public's "purposeless, senseless" use of chance. Genetic variation produced by mutation and recombination has probabilistic (chance) elements-the opposite of what the public thinks of chance.

\section{The Lessons for Your Lessons}

So if we are to expect students to understand scientific uses of terms like cause, chance, and random, we need to be aware that what students hear is generally not going to be what the professor or teacher means. Terms of art like these have specific definitions in the context of science that differ from the meanings students ascribe to them outside of science. Often these terms of art are interpreted in a nonmaterial or religious context, even though these additional meanings are outside of science. If teachers and professors do not recognize these extrascientific understandings of common terms like cause, chance, and random (as well as purpose and design, discussed in our earlier article [Mead and Scott 2010]), they may inadvertently signal to students that their religious views are inherently incompatible with science. Careful and explicit distinguishing of proximate, ultimate, and divine causation - not just in an introductory "nature of science" lesson, but regularly throughout the course in regards to relevant subject matter such as evolution-can help to avoid this. It is critical that supernatural causes be clearly identified as being outside of science.

Similarly, because students often give extrascientific meanings to concepts such as chance and random, tying them to ideas of meaninglessness or purposelessness, it should be made clear that such addenda to the scientific uses of these terms are outside of what scientists can test, and therefore, not considered in a scientific analysis. Students may hold ideas of meaning and purpose that indeed are outside of science and not addressed in a science class, but such ideas are often very important to them. It is one thing to set aside such notions as being outside of the subject area of a science class, and another to dismiss them as unimportant or nonexistent. Doing the latter runs the risk of alienating students from science and impeding their acceptance of evolution and other scientific explanations.

We encourage teachers and professors who teach evolution — or any area of science - to think carefully about how they teach these "problem concepts in evolution": to recognize that they are terms of art in science that have diverse meanings outside of science and to define and use them carefully and explicitly, distinguishing the scientific meanings in context without denigrating extrascientific meanings. It is possible to preserve the integrity of science as a naturalistic way of knowing about nature-indeed, the best epistemology for this purpose-while still leaving open the door for religious students to accommodate a variety of their views with a scientific understanding of the natural world. Inadvertently slamming shut that door by not recognizing the extrascientific meanings students associate with the "problem concepts" defeats the purpose of education.

\section{References}

Anderson DL, Fisher KM, Norman GJ. Development and evaluation of the conceptual inventory of natural selection. J Res Science Teach. 2002;39(10):952-78.

[Anonymous]. Pat Robertson says Haiti paying for "pact to the devil". CNN, January 13, 2010. Available at: http://www.cnn.com/2010/US/ 01/13/haiti.pat.robertson/index.html (retrieved March 25, 2010).

Ariew A. Ernst Mayr's "ultimate/proximate" distinction reconsidered and reconstructed. Biol and Phil. 2003;18(4):553-65.

Benkman CW. Divergent selection drives the adaptive radiation of crossbills. Evolution. 2003;57:1176-81.

Coyne JA, Kay EH, Pruett-Jones S. The genetic basis of sexual dimorphism in birds. Evolution. 2007;61:214-9.

Garvin-Doxas K, Klymkowsky MW. Understanding randomness and its impact on student learning: Lessons learned from building the Biology Concept Inventory (BCI). CBE Life Sci Educ. 2008;7:227-33.

Higher Education Research Institute. A National Study of College Students' Search for Meaning and Purpose. 2005. Available at: http://www.spirituality.ucla.edu/spirituality/reports/FINAL_EX EC_SUMMARY.pdf (accessed March 25, 2010).

Johnson P. Evolution as Dogma. Dallas, TX: Haughton; 1991.

Lynch M, Sung W, Morris K, Coffey N, Landry CR, Dopman EB, et al. A genome-wide view of the spectrum of spontaneous mutations in yeast. Proc Natl Acad Sci. 2008;105:9272-7.

Mayr E. Proximate and ultimate causations. Biol and Phil. 1993;8 (1):93-4.

Mead LS, Scott EC. Problem concepts in evolution part I: Purpose and design. Evol. Edu. Outreach. 2010; in press.

National Science Board. Science and Engineering Indicators 2010. Arlington, VA: National Science Foundation; 2010.

Sinatra GM, Brem SK, Evans EM. Changing minds? Implications of conceptual change for teaching and learning about biological evolution. Evol Edu Outreach. 2008;1:189-95.

Stoinski TS, Vecellioa V, Ngaboyamahina T, Ndagijimana F, Rosenbaum S, Fawcett KA. Proximate factors influencing dispersal decisions in male mountain gorillas, Gorilla beringei beringei. Anim Behav. 2009;77(5):1155-64. 